ENSAYO

\title{
SOBRE EL NEWTONIANISMO Y LA TEORÍA DEL EQUILIBRIO ECONÓMICO GENERAL DE ADAM SMITH*
}

\author{
Leonidas Montes
}

\begin{abstract}
En este ensayo se cuestiona la idea generalizada de que Adam Smith es un pionero de la teoría general de equilibrio económico. Aun cuando la literatura académica acertadamente destaca la influencia de Newton en la obra de Smith, la naturaleza de esta influencia ha sido malinterpretada. En estas páginas se muestra que Smith fue un cuidadoso lector de Newton. Sin embargo la metodología de Newton no necesariamente conduce a una noción de equilibrio como la de la teoría general de equilibrio económico. La interpretación que hace Smith de Newton obedece a una recepción particular y distintivamente escocesa de la obra de Newton, a saber, la de los pensadores de la Ilustración Escocesa. Ellos no atribuyeron a Newton una meto-
\end{abstract}

LeOnidas Montes L. Ingeniero Civil Industrial, Licenciado en Filosofía, Magíster en Ciencia Política (Pontificia Universidad Católica de Chile); MPhil, Ph.D. en Economía (King's College, Universidad de Cambridge). Profesor de economía en la Universidad Adolfo Ibáñez y miembro del Consejo Directivo del Centro de Estudios Públicos.

* “On Adam Smith's Newtonianism and General Economic Equilibrium Theory”, publicado en L. Montes y E. Schliesser (ed.), New Voices on Adam Smith (Londres: Routledge, 2006). Traducción de Estudios Públicos. Publicado en esta edición con la debida autorización.

Para las abreviaciones y referencias de las obras de Adam Smith, véase sección a) de la bibliografía al final del artículo. 
dología axiomático-deductiva. Se sugiere, entonces, que fue la tradición francesa, que interpretó a Newton en el contexto del énfasis cartesiano en la deducción, la que adopta y adapta un newtonismo peculiar, promoviendo una metodología similar a la de Walras, el padre de la teoría general de equilibrio económico.

Hn su clásica e influyente obra Man and Society: The Scottish Inquiry of the Eighteenth Century (1945), Gladys Bryson llamó nuestra atención respecto de la evidente importancia de Newton para la Ilustración Escocesa, vinculando esta influencia a una tradición iniciada por Francis Bacon. Según ella, Adam Smith “ansioso por imponer cierto orden en el caótico ámbito de los fenómenos sociales” ([1945] 1968: 20), piensa que su propia contribución a las “ciencias sociales” se guía por el exitoso modelo de Newton. Smith fue, sin duda, otro heredero de una tradición intelectual que, salvo algunas notables excepciones, veneraba a Newton y su legado. Los descubrimientos de Newton fueron un paradigma ineludible para los posteriores avances científicos, pero la naturaleza del newtonianismo al interior de la Ilustración Escocesa sigue siendo materia de debate.

Una valoración intelectual del contexto del siglo XVIII, que estuvo impregnado por la enorme influencia de Newton, ha llevado a importantes especialistas a evaluar la influencia de éste en Adam Smith. Mark Blaug, una autoridad en la historia del pensamiento económico, sostuvo que el papel fundamental de la simpatía en La Teoría de los Sentimientos Morales (TSM) y del interés propio en La Riqueza de las Naciones (RN) “deben ser considerados como intentos deliberados de Smith por aplicar este método newtoniano primero a la ética y luego a la teoría económica” ([1980] 1992: 52). Andrew Skinner, una autoridad en Adam Smith, también estima que la teoría económica de Smith "fue concebida originalmente a imagen de la física newtoniana” (1979: 110). A decir verdad, Adam Smith fue poderosamente influido por Newton. En consecuencia, según lo interpretan algunos economistas modernos, Smith aplicó el método de Newton a la economía política, lo cual condujo a la formulación de la teoría del equilibrio económico general. El uso de los términos “gravitación” y “centro de reposo”, empleados en el capítulo 7 del libro primero de $R N$, "Del precio natural y de mercado de los bienes”, aportan una sencilla prueba que sustentaría esta percepción. La admiración que Smith siente por Newton, además de la descripción atomística y mecanicista que Newton hace del orden celestial, constituirían una evidencia de que Smith inició la tradición de la teoría del equilibrio económico general basándose en las mismas preconcepciones 
ontológicas. En este ensayo cuestiono esa visión argumentando que es acertado subrayar la influencia de Newton sobre Smith, pero por motivos distintos. Si bien Smith fue un verdadero newtoniano, su metodología no necesariamente conduce a una noción de la teoría del equilibrio económico general. Tampoco se funda enteramente en una metodología axiomáticodeductiva. Ella ha sido generalmente atribuida a Newton, pero el newtonianismo no fue concebido de esa manera por la Ilustración escocesa. Fueron los franceses quienes adoptaron y adaptaron un newtonianismo axiomáticodeductivo fomentando el uso de una metodología similar a la de Walras, el verdadero padre de la teoría del equilibrio económico.

En la primera sección demostraré que la metodología de Newton es mucho más compleja y sutil de lo que comúnmente se piensa. Describiré el método newtoniano de análisis (método de resolución) y síntesis (método de composición), lo mismo que su concepción de un método potencialmente abierto de aproximación sucesiva. En la segunda sección analizaré ampliamente la manera en que Smith aborda el pensamiento de Newton, con especial énfasis en el capítulo 7 de $R N$. En la última sección haré particular hincapié en el contexto de la Ilustración Escocesa. Sostengo que las intenciones de Smith en su ensayo History of Astronomy son consecuencia de una interpretación particular y claramente escocesa del pensamiento de Newton. Pretendo mostrar no sólo que Adam Smith fue un esmerado intérprete de Newton, sino que además dominaba la metodología newtoniana de una manera muy sofisticada. Esta investigación concluye con una breve reflexión sobre en enfoque metodológico aplicado en este ensayo, y su importancia para nuestra comprensión del newtonianismo de Smith.

\section{La metodología de Newton}

Tras leer algunos de los manuscritos de Newton, John Maynard Keynes fue tal vez el primero en revelar la otra cara del padre de la ciencia moderna. En 1936, en un remate efectuado en la Casa Sotheby's, se vendieron a un precio bastante módico 329 lotes de manuscritos de Newton, que contenían cerca de 3 millones de palabras. Keynes se las ingenió para comprar y gradualmente reagrupar más de un tercio de la colección (Spargo, 1992). Luego de evaluar esta evidencia de primera mano, en su obra póstuma Newton, the Man ${ }^{1}$, Keynes escribió: “Newton no fue un adelantado en

\footnotetext{
${ }^{1}$ Hasta donde yo sé, este ensayo fue leído póstumamente por sir Geoffrey Keynes (hermano de John Maynard Keynes) en julio de 1946, dentro del marco de las celebraciones del tricentenario del nacimiento de Newton que tuvieron lugar en el Trinity College. Gleick (2003: 188) plantea que el ya difunto John Maynard Keynes habría leído este ensayo.
} 
la era de la razón. Fue el último de los magos, el último de los babilonios y sumerios” (Keynes, 1972: 364). Mientras la reputación de Newton se basó en sus descubrimientos científicos en el área de la mecánica, la cosmología, la óptica y las matemáticas, el hecho de que dedicara considerables energías a estudiar la alquimia, la teología, las profecías y la sabiduría antigua simplemente había pasado inadvertido. Tras la publicación del innovador ensayo de Keynes, diversas biografías han ofrecido una descripción más imparcial y objetiva del verdadero Newton ${ }^{2}$, lo cual ha generado un renovado interés por la "ciencia privada" de Newton.

Newton no sólo era excepcionalmente versado en obras sobre alquimia, sino además un destacado practicante de la misma. Era también un voraz lector de las Sagradas Escrituras y de tratados teológicos. Convencido de que los sabios antiguos conocían la ley de la gravitación universal, dedicó gran parte de sus energías a estudiar las profecías en el Libro de Daniel y en el Libro de la Revelación. Hoy en día los especialistas convendrían en que las especulaciones de Newton acerca de la naturaleza de la materia podrían haber sido influidas por sus conocimientos sobre alquimia, teología y sabiduría antigua. Como lo señaló acertadamente Patricia Fara: "para él la gravedad, la alquimia y Dios estaban íntimamente ligados [...] las actividades alquímicas de Newton no estaban subordinadas a su filosofía natural, sino que más bien eran un componente esencial de su empeño religioso por estudiar las actividades de Dios desde tantos aspectos como fuera posible” (2003: 501). Ahora bien, ¿cuál es la verdadera naturaleza del newtonianismo? Antes de responder esta pregunta, primero debemos investigar lo que Newton dijo sobre su metodología.

Principia y Opticks son las fuentes públicas más importantes para comprender el método de Newton. El título completo de Principia (Philoso-

${ }^{2}$ Las obras clásicas sobre la vida de Newton son las escritas por Bernard le Bovier de Fontenelle, quien publicó en 1728 The Elogium of Sir Isaac Newton; William Stukeley, amigo y seguidor de Newton, quien escribió en 1752 Memoirs of Sir Isaac Newton's Life, y la obra en un tomo de sir David Brewster, titulada The Life of Sir Isaac Newton (1831), seguida de Memoirs of the Life, Writings, and Discoveries of Sir Isaac Newton (1855), obra en dos tomos. Esta última fue considerada la biografía clásica de Newton como padre de la "Era de la Razón”. Aun cuando desde el ensayo de Keynes se han escrito muchas biografías de Newton, a mi juicio Never at Rest: A Biography of Isaac Newton (1980), de Richard Samuel Westfall, sigue siendo la mejor relación de la vida de Newton y de su contexto intelectual (una versión condensada y titulada The Life of Isaac Newton fue publicada en 1993). Portrait of Isaac Newton (1968), de F. E. Manuel, entrega una interpretación polémica y más bien freudiana del pensamiento de Newton; Isaac Newton: Adventurer in Thought (1992), de A. R. Hall, es también una excelente biografía; y por su parte M. White (Isaac Newton: The Last Sorcerer, 1998) y J. Gleick (Isaac Newton, 2003), han publicado buenas biografías de Newton. 
phiae Naturalis Principia Mathematica) se asemeja a Principia Philosophiae de Descartes $(1644)^{3}$ y explícitamente pretende reemplazarlo. El magnum opus de Newton fue escrito deliberadamente "de manera matemática", con el objetivo expreso de evitar "ser provocado por personas con escasos conocimientos de matemáticas" (citado en Westfall, 1980: 459). Aun cuando resulta innegable que las matemáticas cumplen un papel esencial en el desarrollo de la metodología de Newton, uno de los mayores logros de la "filosofía experimental” de Newton reside en su método de resolución (análisis) y de composición (síntesis). En su famoso General Scholium, anexado al final de la segunda edición de Principia, Newton se refiere a la naturaleza de su "filosofía experimental" en la cual "las proposiciones se deducen de los fenómenos y se generalizan por inducción” (Newton, [1687] 1999: 943). En la última cuestión, la $\mathrm{N}^{0} 31$, de Opticks ${ }^{4}$ declara que "el análisis consiste en realizar Experimentos y Observaciones, y en extraer de ellos Conclusiones generales por Inducción [...] La síntesis consiste en dar por sentadas las Causas descubiertas y establecidas como Principios, y a partir de éstas explicar los Fenómenos que se originan en ellas” (Newton, [1704] 1979: 404405). En suma, el método de resolución nos permite inferir causas a partir de los fenómenos, y el método de composición un principio (o algunos principios) a partir del cual (o de los cuales) podemos explicar otros fenómenos (en lo concerniente a este tema y su relación con Smith conviene ver visiones distintas en Hetherington 1983 y Montes 2003).

${ }^{3}$ La primera edición fue publicada en 1687, gracias a Edmond Halley, por la Royal Society; la segunda, compilada por Roger Cotes, fue publicada en 1713; y la tercera, compilada por Henry Pemberton, en 1726. La primera traducción al inglés de Principia de Newton fue realizada por Andrew Motte y publicada póstumamente en 1729. Una versión revisada por Florian Cajori fue publicada en 1934, y en 1999 Bernard Cohen y Anne Whitman publicaron la nueva y largamente esperada traducción completa de Principia, precedida por A Guide to Newton's Principia, la excelente obra de Cohen.

${ }^{4}$ Después de ser nombrado presidente de la Royal Society en 1703, Newton siguió el consejo de John Wallis de publicar su obra sobre óptica. La primera edición de Opticks salio finalmente a luz en 1704, treinta años después de escrita, y sólo un año después del fallecimiento de Hooke, su rival de toda la vida (Newton había prometido no publicarla mientras aquél estuviera vivo). En la Advertencia a la primera edición, Newton explicaba que había prohibido la publicación de esta obra desde 1675 a fin de “evitar enfrascarse en polémicas”. La última cuestión, la número 31, fue añadida para aparecer en la primera edición en latín, Optice, publicada en 1706. Esta última fue traducida y prologada por Samuel Clarke, amigo y acérrimo partidario de Newton. En la edición latina se agregaron 7 nuevas preguntas (25 a 31), y en la segunda edición en inglés, publicada en 1717, se incorporaron otras 8 cuestiones (17 a 24). 
Al final del primer párrafo del prólogo de Principia, preocupado y consciente de la naturaleza desconocida de la fuerza de gravedad, Newton especula que

Muchas cosas me llevaron a abrigar la sospecha de que todos los fenómenos pueden depender de ciertas fuerzas mediante las cuales las partículas de los cuerpos, por causas aun desconocidas, o bien son impelidas unas hacia las otras hasta cohesionarse para formar figuras regulares, o bien se repelen unas a otras y se apartan. Como estas fuerzas son desconocidas, las pruebas en la naturaleza realizadas hasta ahora por los filósofos han sido inútiles. (Newton, [1687] 1999: 382-383.)

Y concluye que: "Sin embargo, espero que los principios aquí establecidos arrojarán algo de luz sobre este modo de filosofar o sobre alguno más preciso" (ibídem, sin destacar en el original). Este es el gran problema que enfrentó Newton respecto a la cuestión de la fuerza de gravedad. Newton fue atacado por recurrir a cualidades ocultas, ya que estaría siguiendo la desacreditada tradición aristotélico-escolástica. Sus esfuerzos por rebatir esta acusación, o por explicar su sistema, revelan otra faceta muy interesante de la metodología de Newton: un deseo de descubrir la verdadera naturaleza de las cosas, el cual —y esto es fundamental — incluso admite la existencia de otra posibilidad (recuérdese "o alguno más preciso").

Por otra parte, al referirse a la atracción en la última cuestión de Opticks, el padre de la ley de la gravitación universal también estaba abierto a la eventualidad "de que pudiera haber más poderes de Atracción" (Newton, [1704] 1979: 376). Asimismo, las cuatro "reglas para el estudio de la filosofía natural" se han transformado en una herramienta emblemática para comprender la "filosofía experimental" de Newton. En particular, la polémica regla 4, que fue agregada en la tercera edición de Principia, establece que:

En la filosofía experimental, las proposiciones reunidas a partir de los fenómenos por inducción deberían considerarse absolutamente verdaderas o muy cercanas a la verdad pese a cualquier hipótesis contraria, hasta que surjan otros fenómenos en virtud de los cuales dichas proposiciones aumenten su exactitud o queden sujetas a excepciones. (Newton, [1687] 1999: 796.)

Esta afirmación es muy distinta de la visión comúnmente aceptada sobre el legado de Newton. En lugar de un énfasis en el carácter apodíctico 
de una teoría, o una preocupación por sus poderes explicativos permanentes, Newton se limita a dejar las teorías como proposiciones abiertas. Se trata de una importante evidencia que corrobora que un modelo axiomáticodeductivo de ciencia no es herencia de Newton ni de Smith, como quedará demostrado en la siguiente sección. Schliesser (2005) ha aportado evidencias adicionales y sustanciales para interpretar la teoría newtoniana de la ciencia de Smith como una herramienta de investigación para un proceso potencialmente abierto de aproximación sucesiva ${ }^{5}$. Newton acepta que el progreso de la filosofía natural es abierto, sosteniendo la existencia de la verdad provisional hasta que se pruebe lo contrario. Por añadidura, no considera las regularidades de los fenómenos matemáticos como el sello distintivo del progreso científico. Para Newton, las leyes, incluida la ley de gravedad, pueden ser susceptibles de perfeccionamiento como parte de este proceso de aproximación sucesiva. Adam Smith, como se demostrará luego, comprendió claramente esta visión 6 .

Como primero se publicó en inglés, Opticks de Newton fue más popular, y por cierto más accesible al público general ${ }^{7}$. Además, él concluye su obra "proponiendo sólo algunas cuestiones, para permitir que otros lleven a cabo una indagación más amplia" (Newton, [1704] 1979: 339). Esta sucesión de 31 cuestiones ofrece la oportunidad para leer las especulaciones y las propuestas de investigación de Newton acerca de muchos temas complejos. La teoría corpuscular de la luz entrañaba cuestiones difíciles, en especial sobre la naturaleza interna de la materia. Concretamente, al final de la cuestión 28 se formula otra importante insinuación respecto de la verdadera metodología de Newton:

${ }^{5}$ En efecto, Bernard Cohen, George Smith y Howard Stein son los principales pensadores newtonianos que han investigado el compromiso de Newton con un proceso abierto de aproximación sucesiva. Por ejemplo, Smith (2002: 159) se refiere a la regla 4 sosteniendo que "quam proxime equivale a una estrategia probatoria con miras a investigaciones ulteriores", y luego brillantemente subraya que "el proceso de aproximaciones sucesivas derivado de Principia de Newton ha arrojado en estos ámbitos evidencias de una calidad que supera cualquier cosa con que sus predecesores soñaron alguna vez" (ibídem: 162).

${ }^{6}$ Andrew Skinner $(1979,2001)$ ya había destacado las conexiones entre Smith, Kuhn y Shackle en cuanto a su filosofía de la ciencia, pero Schliesser es más preciso al considerar a "Smith como un realista frente a la teoría de Newton". Para un excelente análisis de éste y otros aspectos, véase también Smith (2002) y Stein (2002).

${ }^{7}$ Esta sencilla diferencia entre ambas oeuvres conlleva además dos "tradiciones bastante distintas de hacer ciencia” (véase Cohen y Smith 2002: 31). Sin embargo, yo agregaría que desde un punto de vista metodológico, como se sugerirá implícitamente en este ensayo, más que diferencias entre las primeras ediciones de las obras de Newton y las que publicó al final de su vida, se observa una evolución metodológica. 
Y aunque cada Paso verdadero que se da en esta Filosofía no nos conduce inmediatamente al Conocimiento de la primera Causa, de todos modos nos conduce cerca de ella, y por ese motivo debe ser altamente valorado. (Ibídem: 370.)

En la última cuestión, la número 31, Newton continúa explicando este argumento:

Y si no surge ninguna Excepción derivada de los Fenómenos, se puede enunciar la Conclusión en un sentido general. Pero si en cualquier momento posterior surgiere alguna Excepción derivada de los Experimentos, entonces se debería comenzar a enunciarla incluyendo esas Excepciones a medida que se presenten. Siguiendo esta modalidad de análisis, podemos proceder [...] en general, desde los Efectos hasta sus Causas, y desde las Causas más particulares hasta las más generales, hasta que el Argumento concluya en la más general. Éste es el Método de Análisis: Y la Síntesis consiste en dar por sentadas las Causas descubiertas y establecidas como Principios, y a partir de ellas explicar los Fenómenos que proceden de ellas, y demostrando las Explicaciones. (Ibídem: 404-405.)

Estos pasajes constituyen una clara reflexión sobre el método de Newton de aproximación a la realidad ${ }^{8}$. Sin negar la verdad, él confía en que las desviaciones de los fenómenos reales efectivamente apuntalen el progreso del conocimiento científico. Si no hay desviaciones, nuestras conclusiones se mantendrán, pero si de verdad llegan a surgir disociaciones a partir de los fenómenos, simplemente debemos intensificar la búsqueda de la verdad científica mediante análisis reiterativos que lograrán conducirnos con éxito a una nueva síntesis. Con todo, este tipo de metodología dialéctica reconoce no sólo un proceso de aproximación sucesiva a la realidad, sino además una priorización del método de resolución (o análisis). Efectivamen-

${ }^{8}$ En Montes (2003: 741-743), señalé algunas similitudes entre el método real de Newton y el enfoque conocido en economía como "realismo crítico". Un año después de aparecido ese trabajo se publicó The Cambridge Companion to Newton. En esta obra, el editor, George E. Smith, en su ensayo "The Methodology of Principia", analiza las cuatro reglas de Newton y se refiere a la segunda de ellas, señalando que "efecto similar, causa similar, da pie para inferencias que Charles Saunders Peirce habría calificado de abductivas en contraste con inductivas” (Smith, 2002: 160-161; destacado en el original). Considerando que el realismo crítico ha defendido un modelo de inferencia retroductivo que se asemeja mucho a la inferencia abductiva de Peirce (véase Lawson, 1997: 294, n. 14), resulta alentador leer a un eminente pensador como George E. Smith estableciendo el mismo vínculo. 
te: "en la Filosofía Natural, la Investigación de las Cosas difíciles empleando el método de Análisis debe siempre preceder al Método de Composición" (ibídem: 404). Se trata de un aspecto esencial que ha sido relativamente ignorado: el análisis precede la síntesis, y más aun, tiene preeminencia sobre ella ${ }^{9}$.

Por mucha cautela que demuestre frente a la verdad, Newton nunca niega su existencia. De hecho, en la visión de Newton del progreso científico está insinuado su realismo. En General Scholium él se refiere a Dios y a la gravedad. Tal vez teniendo en mente a Nicholas Saunderson (1682-1739), el famoso matemático ciego, Newton establece una analogía entre Dios y los colores. "Así como un ciego no tiene noción de los colores” (Newton, [1687] 1999: 942), lo propio ocurre con Dios. La realidad no necesariamente se torna en algo manifiesto. Luego, al tratar de descubrir la causa de la gravedad, Newton sostiene que lo que realmente importa es que la gravedad "existe" (ibídem: 943). Éste no sólo es el mejor ejemplo para comprender lo que Eric Schliesser ha denominado el "realismo modesto" de Newton, sino además es con toda probabilidad la fuente de la tardía preocupación de Newton por la metodología ${ }^{10}$. Newton tenía la respuesta sobre la manera en que funcionaba el mundo, pero no sabía por qué funcionaba de ese modo. En otras palabras, podía describir la gravedad como causa, pero no podía explicar sus poderes causales.

Sólo me he concentrado en Principia y en Opticks, pero cabe mencionar que los trabajos no publicados de Newton efectivamente aportan evidencias adicionales para la interpretación que he estado tratando de de-

${ }^{9}$ En la edición Glasgow de la colección de ensayos de A. Smith, Essays on Philosophical Subjects (EPS), los editores señalan acertadamente en su introducción que "La metodología de Smith parecería adaptarse a las exigencias del método newtoniano propiamente tal por cuanto él usaba las técnicas de análisis y síntesis en el orden apropiado" (EPS, 12).

${ }^{10}$ En un ensayo muy sugerente, Strong (1952) sostuvo la existencia de una suerte de "Problema de Newton" (a la manera de Smith), ya que en las ediciones originales de Principia y Opticks no se hace referencia a Dios (el General Scholium se añadió 25 años después de la primera edición de Principia en 1687, y las cuestiones en que se menciona a Dios aparecieron por primera vez en la edición latina Optice en 1706, y especialmente en la segunda edición inglesa de 1718). Por cierto que la necesidad de Newton de explicar de alguna manera la causa de la gravedad —la principal crítica que le dirigían los cartesianos- podría haber influido en su decisión de recurrir a un argumento teológico. Pero a mi juicio el argumento de Strong puede hacerse extensivo a la preocupación de Newton por su metodología como un proceso abierto de aproximación sucesiva. Resulta innegable que Newton tenía plena conciencia de su filosofía experimental, pero sus obras adquirieron matices cada vez más significativos a medida que fue envejeciendo. 
sarrollar ${ }^{11}$. Para citar sólo un ejemplo, en un fragmento que probablemente iba a ser incluido en Opticks, Newton se refiere al método de resolución y composición, añadiendo que "quien espera lograr éxito, debe resolver antes de componer. Pues la explicación de los Fenómenos son Problemas mucho más complejos que aquellos de las Matemáticas” (McGuire, 1970: 185). El progreso científico no sólo consiste en limitarse a alcanzar una regularidad matemática, ni tampoco esta última es una condición previa del método de Newton. Si sus descubrimientos crearon un sistema matemático de la naturaleza, ello no necesariamente implica que la filosofía natural de Newton favoreciera una determinada interpretación matemático-positivista de su método $^{12}$.

\section{Smith acerca de Newton}

Dejando de lado por el momento Essays on Philosophical Subjects (EPS), con sus numerosas referencias a Newton principalmente en el ensayo "History of Astronomy", se observan escasas alusiones directas a Newton en las otras obras de Smith: ninguna en La Riqueza de las Naciones $(R N)$, algunas en Lectures on Rhetoric and Belles Lettres (LRBL), una en Lectures on Jurisprudence ( $L J$ ) y una en La Teoría de los Sentimientos Morales (TSM). Pero la única referencia a Newton en TSM, en el capítulo 2, tercera parte, se encuentra dentro de un interesante pasaje incorporado en la sexta edición. Tras advertir la sensibilidad de los poetas y hombres de letras frente a la opinión pública, Smith continúa declarando que "Los mate-

${ }^{11}$ Por ejemplo, Kuhn subraya que aun cuando Newton "al parecer ha respaldado la posterior aseveración de que la investigación científica puede y debe estar limitada a la búsqueda experimental de la regularidad matemática [...], un cuidadoso análisis de los escritos menos sistemáticos de Newton que han sido publicados no proporciona ninguna evidencia de que éste se haya impuesto una restricción tan drástica a la imaginación científica” (1958: 45).

12 Para una profundización de esta visión, véase Montes (2003: 725-732). Strong (1951) investiga la "vía matemática" de Newton y advierte no sólo que su método de las fluxiones es ante todo geométrico, sino además sostiene la existencia de un "experimentalismo matemático en el que las mediciones y las reglas de medición preparan los principios mecánicos” (ibídem: 107). Para Newton las matemáticas "son una herramienta concebida para ayudar a resolver problemas científicos” (ibídem). Por otra parte, defiende la tesis de un "conceptualismo matemático" newtoniano seguido por McLaurin, Pemberton y Gravesande, el cual contrasta con el "realismo matemático" de Keill (Strong, 1957). Asimismo, en las visiones de Newton sobre las matemáticas la geometría ocupa un lugar preponderante. La manera en que desarrolló su "cálculo de fluxiones" (cálculo diferencial), lo mismo que su "método de las cantidades que fluyen o fluentes” (cálculo integral), reflejan la importancia que asignó a la geometría clásica por sobre las matemáticas puras (véase especialmente Guicciardini 1989, 1999, 2002). 
máticos, por el contrario [...] suelen ser muy indiferentes ante la recepción que puedan encontrar en el público" (TSM III.3.20, 124). Menciona a Robert Simson y a Matthew Stewart como sus ejemplos de primera mano. Luego escribe:

Se me ha dicho que Mathematical Principles of Natural Philosophy, la gran obra de Sir Isaac Newton, fue ignorada por el público durante varios años. Es probable que la serenidad de un gran hombre nunca se haya visto interrumpida por ese motivo siquiera durante un cuarto de hora. Los filósofos naturales, dada su independencia de la opinión pública, se aproximan mucho a los matemáticos, y en sus juicios relativos al mérito de sus propios descubrimientos y observaciones, disfrutan en cierto grado de la misma seguridad y serenidad. (Ibídem.)

\section{Smith continúa añadiendo que:}

Los matemáticos y los filósofos naturales, dada su independencia de la opinión pública, no se sienten demasiado tentados a organizarse en facciones y camarillas, ya sea para respaldar su propia reputación, ya sea para rebajar la de sus rivales. Casi siempre se trata de hombres cuyos sencillos modales reflejan una extremada afabilidad, que conviven en un clima de gran armonía, y defienden mutuamente su reputación, que no participan en ninguna intriga para conseguir la aprobación pública, sino que se sienten complacidos cuando sus obras son objeto de aprobación, y no experimentan gran fastidio o ira cuando ellas son ignoradas. (TSM III.2.22, 125)

Ésta es una de las escasas ocasiones en que alude directamente a Newton, y vale la pena analizar su contenido. Cuando Smith señala haber escuchado que Principia de Newton había sido ignorada por el público, su fuente fue probablemente Robert Simson, su profesor de matemáticas en Glasgow. No obstante, tras presentar su visión de Newton y los filósofos naturales, Smith no sólo se transformó en otro heredero de la imagen altamente idealizada de Newton, sino además en un idealista respecto de los matemáticos en general. Él ignora el acalorado debate entre Newton y Leibniz en torno a la invención del cálculo, y contempla ingenuamente a los matemáticos haciendo caso omiso de las intrigas y las facciones que conocemos hoy en día. Presumo que la primera actitud podría reflejar la percepción general de Newton como el héroe intelectual británico que poseía las 
claves de la naturaleza ${ }^{13}$, y la segunda probablemente fue influida por su familiaridad personal con algunos matemáticos escoceses, tal vez principalmente Simson ${ }^{14}$.

La visión de Smith sobre la metodología de Newton se encuentra en su ensayo "History of Astronomy" (incluido en su colección de ensayos titulada Essays on Philosophical Subjects, EPS), "la perla de la colección" según Schumpeter (1994 [1954]: 182). En 1773, encontrándose enfermo, Smith envió una alarmante carta a Hume en la que declaraba:

Como he dejado a su cuidado todos mis trabajos literarios, debo decirle que con excepción de aquellos que llevo conmigo no hay ninguno que merezca ser publicado, salvo un fragmento de una gran obra que contiene una historia de los sistemas astronómicos que estuvieron sucesivamente en boga hasta la época de Descartes. Si aquello podría o no ser publicado como fragmento de una obra en ciernes escrita en la juventud, lo dejo enteramente a su criterio; aunque comienzo a sospechar que en algunos pasajes de ella hay más refinamiento que solidez. (Corr., 168)

Lo anterior demuestra que aun cuando Smith estaba decidido a rescatar su "History of Astronomy" (en lo sucesivo "Astronomy") de la hoguera, ya que pensaba que su enfermedad sería terminal, no estaba plenamente convencido de su calidad. De todos modos, como la modestia de Smith queda de manifiesto en toda su correspondencia, podría tratarse simplemente de una frase retórica y cortés dirigida a su amigo Hume. La calidad de "Astronomy" ha sido materia de debates. Para algunos especialistas no es más que una obra "de juventud"15, que podría haber sido escrita mientras estudiaba en Oxford. No obstante, los editores de la Glasgow Edition estiman que "Astronomy" "constituye uno de los mejores ejemplos de historia teórica" (EPS, 2), y concluyen que "la visión de Smith sobre la ciencia

${ }^{13}$ Simplemente reacuérdese el epitafio que Alexander Pope dedicó a Newton. “La naturaleza y sus leyes yacían ocultas en la noche/ Dijo Dios ‘ique sea Newton!’ y todo se hizo luz" (1730). Voltaire y Fontenelle podrían haber inspirado a Smith en esta visión, por cuanto se refieren a la tranquilidad de ánimo de Newton. De hecho, poco después del último pasaje citado de TSM, Smith se refiere a Fontenelle, quien, al escribir sobre matemáticos y filósofos naturales, "tiene frecuentes oportunidades de celebrar la amable simplicidad de sus modales” (TSM III.2.23, 125).

${ }^{14}$ De acuerdo con Alexander Carlyle, Robert Simson era "de carácter apacible y aire cautivador, y dominaba todos los conocimientos [...], los que impartía con un estilo coloquial y llano, con la sencillez de un niño, sin el menor síntoma de autosuficiencia o arrogancia” (citado en Ross 1995: 46).

${ }^{15}$ Fue escrito definitivamente antes de 1758 (cf. “Astronomy” IV.75, 103). 
parece más perspicaz hoy en día que lo que habría podido parecer en el siglo XVIII" (ibídem: 21). Pero poco después, Wightman, editor de EPS, consideró que "un especialista contemporáneo no recurriría [a] ninguno de ellos [los principales ensayos de Smith] para obtener una visión más clara sobre la historia de las ciencias" (EPS, 5). Concretamente, "Astronomy", "[si] bien resulta aceptable para un historiador moderno en sus aspectos principales, contiene numerosas omisiones graves y tantos errores de detalle que no pasa de ser una pieza de museo en su especie" $(E P S, 11)^{16}$. La verdadera naturaleza de la metodología de Newton sugerida en "Astronomy" ha sido relativamente ignorada en comparación con los comentarios y las investigaciones sobre la tríada "sorpresa, maravilla y admiración”, y se podría afirmar que incluso ha sido subestimada. Por ejemplo, Longuet-Higgins concluye que "el enfoque que Smith aplicó a la historia de la astronomía fue el de un psicólogo y no el de un filósofo de la ciencia” (1992: 91) ${ }^{17}$.

Smith refleja la reacción británica ante la filosofía mecánica. Él se refiere a Descartes como "ese filósofo genial y extravagante" ("Astronomy" IV.61, 92). En "Astronomy” él comprendió claramente la manera en que el sistema de Newton había superado la teoría cartesiana de los vórtices. El título completo de este ensayo es "The Principles Which Lead and Direct Philosophical Enquiries; Illustrated by the History of Astronomy", y su importancia metodológica llama inmediatamente nuestra atención. Si bien se inicia con una descripción psicológica del progreso científico, es posible extraer algunas conclusiones metodológicas. Sorpresa, maravilla y admiración son etapas sucesivas que conducen hacia el progreso científico. Las etapas psicológicas que van desde "lo inesperado", pasando por "lo nuevo y singular", hasta culminar en "lo grande y hermoso", respectivamente, constituyen el fundamento para comprender la naturaleza del progreso científico como un proceso mental abstracto. A pesar de que esta abstracción subyacente al proceso científico ya está presente en los clásicos, resulta notable la forma en que Smith sitúa su historia dentro de este proceso psicológico. Este último, en cuanto abstracción, sienta las bases de la astro-

${ }^{16}$ También Cleaver (1989), al contrastar el discurso teórico con el científico, recurre a la astronomía, identificando tres principios en la presunción básica de que existe una suerte de equilibrio o uniformidad que mueve a Smith a adoptar una epistemología que carece de un marco ambiental y cultural. Discrepo de esta presunción.

${ }^{17}$ Contradiciendo la visión tradicional, Bernard Cohen sugirió que "Smith era muy versado en ciencia newtoniana” (1994: 66). Schliesser (2005 y otro trabajo de próxima aparición) y Montes (2003) han intentado restablecer la importancia metodológica de la astronomía de Newton, especialmente en algunos de sus aspectos newtonianos. 
nomía y se transforma en su antecedente ${ }^{18}$, pero su historia tiene una naturaleza peculiar.

Smith define el papel del filósofo como el estudio "de los principios conectores de la naturaleza” (“Astronomy” II.12, 45), una definición que persiste durante todo este ensayo. A decir verdad, esta idea de "mantener conectado" exige que algo sea conectado, lo cual implica que esas conexiones existen. Es más, antes de proceder a desarrollar su visión en “Astronomy" Smith señala:

Procuremos rastrearla, desde su origen mismo, hasta esa cumbre de perfección que supuestamente ha alcanzado en la actualidad, y que, en realidad, también se supone que ha alcanzado en casi todas las épocas pasadas [...]. Analicemos, por tanto, todos los distintos sistemas de la naturaleza ... [que] las personas instruidas e ingeniosas han adoptado sucesivamente. (“Astronomy” II.12, 46)

La naturaleza condicional del progreso científico implícita en este pasaje, en una época que consideraba los descubrimientos de Newton como el clímax científico per se, es un aspecto ignorado de la interpretación de Newton por parte de Smith. Para Smith la ciencia es un proceso abierto de aproximaciones sucesivas que se asemeja al legado metodológico real de Newton. Newton descubrió que

Podía vincular los movimientos de los planetas mediante un principio de conexión tan familiar que eliminaba completamente todas las dificultades que la imaginación había experimentado hasta entonces para concentrarse en ellos [...]. Habiendo entonces demostrado que la gravedad podría ser el principio conector que mantenía unidos los movimientos de los Planetas, él posteriormente se empeñó en demostrar que ello realmente ocurría. (“Astronomy” IV.67, 98, sin destacar en el original.)

El uso de Smith del condicional podría no es casual; sólo refuerza mi argumento.

Smith concluye su análisis de los descubrimientos de Newton con la siguiente frase: “Tal es el sistema de Sir Isaac Newton, un sistema en que la

${ }^{18}$ Sin embargo, cabe hacer la advertencia de que al final de su ensayo sobre astronomía Smith recurre a su intención original: "mientras hemos estado empeñados en representar todos los sistemas filosóficos como meras invenciones de la imaginación, en aunar los de otro modo inconexos y discordantes fenómenos de la naturaleza" (“Astronomy” IV.76, 105). 
totalidad de sus partes se encuentran más estrictamente conectadas que las de cualquier otra hipótesis filosófica” (“Astronomy” IV.76, 104, sin destacar en el original). Tampoco es casual en este caso el uso de Smith del adverbio más. La idea recurrente de conexiones que existen en la naturaleza se encuentra escépticamente sujeta a una aproximación en la visión que Smith presenta de Newton. La idea de que "la gravedad podría ser el principio conector", o la descripción del sistema de Newton como "un sistema en el que la totalidad de sus partes se encuentran más estrictamente conectadas”, simplemente refleja que el sistema de Newton es el más preciso que la humanidad ha logrado alcanzar, pero no la verdad definitiva. El éxito científico de Newton con sus principios de conexión mueve a Smith a aseverar que deberíamos considerar sus principios "como si fueran las verdaderas cadenas que la Naturaleza emplea para enlazar sus diversas operaciones” (“Astronomy" IV.76: 105, sin destacar en el original). Nótese una vez más el empleo de la frase comparativa "como si". En realidad, estos ejemplos demuestran que Smith comprendía cabalmente la naturaleza abierta de la indagación científica. Se trata de una propiedad característicamente newtoniana, como hemos demostrado en la sección anterior de este capítulo. Smith estaba consciente de que podíamos aproximarnos sucesivamente a la realidad, postura que también es muy newtoniana.

Pasemos ahora a analizar a Smith y su teoría del equilibrio económico general. En su monumental obra History of Economic Analysis, Joseph Schumpeter, quien no era un aficionado a Adam Smith, elogia "la rudimentaria teoría del equilibrio expuesta en el capítulo 7 [Riqueza de las Naciones, $R N$ ], lejos la mejor obra sobre teoría económica escrita por Adam Smith” (1994 [1954]: 189), simplemente porque sería una antecesora teórica orientada hacia Walras. Al referirse a los precios y las cantidades que constituyen "el 'sistema' económico", si Isnard, Smith, Say y Ricardo "luchaban por alcanzarlo o más bien lo buscaban a tientas", para Schumpeter fue Walras quien realizó el "descubrimiento" del equilibrio económico, "la Carta Magna de la teoría económica” (ibídem: 242). Desde entonces ha existido un consenso general en cuanto a que Smith sería un precursor, cuando no el fundador, de la teoría del equilibrio económico general ${ }^{19}$. Algunos econo-

${ }^{19}$ Por ejemplo, Lionel Robbins elogia el logro de $R N$, que está “en consonancia con el aparato más refinado de la moderna Escuela de Lausana” (1962 [1932]: 69). Samuel Hollander, aplicando nuestros conocimientos modernos sobre el equilibrio general a una concepción del mecanismo de precios de Smith, se refiere al "notable capítulo” (1973: 117). Más adelante sostiene que "aun así una orientación hacia Riqueza de las Naciones basada en la teoría de los precios no ha sido refutada” (Hollander, 1987: 61), concluyendo que el Capítulo 7 “contiene una formulación embrionaria de la teoría 
mistas modernos, considerando el equilibrio económico general walrasiano como "la cumbre de la teoría económica neoclásica” (Samuelson, 1952: 61), concluyen que Adam Smith, "padre de nuestra ciencia”, podría tener razones más poderosas para reivindicar ese título. Por añadidura, la más famosa (y más esquiva) metáfora en la historia del pensamiento económico, la de la mano invisible, ha sido interpretada como "una expresión poética" que confirma a Smith como "un creador de la teoría del equilibrio general” (Arrow y Hanh, 1971: 2). De cualquier manera, en los textos de microeconomía no se vacila en vincular la mano invisible de Smith con algún tipo de equilibrio ${ }^{20}$.

El empeño general de Smith por revelar la naturaleza de la economía política, y en particular por iluminar "los particulares accidentes [...], causas naturales, y $[\ldots]$ particulares regulaciones” ( $R N$ I.vii.20, 77) del mecanismo de mercado, es newtoniano desde el punto de vista de su metodología y su realismo. Él no previó un modelo teórico del mecanismo de mercado a partir del cual puede deducirse una confluencia de fenómenos, como Schumpeter podría haber deseado. Su amplio proyecto de una ciencia social que incluyera la ética, la jurisprudencia y la economía política consistía en determinar las verdaderas estructuras que subyacen tras los fenómenos sociales. Su búsqueda intelectual se relaciona con la "naturaleza y las causas" (recuérdese el título completo de $R N$ ) de los fenómenos sociales. Tanto Newton como Smith reaccionan oponiéndose a la reducción de los fenómenos a causas mecánicas, compartiendo un proyecto filosófico común. Por tanto, no es coincidencia el que lo expresado por Smith en "Astronomy" refleje un realismo profundamente imbuido de la influencia de Newton. El objetivo de nuestras indagaciones es "poner al descubierto las conexiones ocultas que unen las diversas apariencias de la naturaleza” (“Astronomy” II.3: 51). Al contrario de lo sugerido por Blaug, quien sostiene que Smith "tenía una visión ingenua de lo que constituía el método de Newton” ([1980] 1992: 53), lo anterior aporta evidencia adicional para probar que Smith comprendía el pensamiento Newton mejor de lo que generalmente se ha admitido.

del equilibrio general” (ibídem: 65). Buchanan y Yoon (2000) estiman que las utilidades crecientes de que habla Smith son compatibles con el equilibrio competitivo. Lo anterior sugeriría que Smith fue un precursor del equilibrio competitivo como estado final. Para puntos de vista distintos, véase Chandra (2004) y Negishi (2004).

${ }^{20}$ En Microeconomic Theory, la popular obra de Mas-Collel y otros, se lee: “El primer teorema fundamental de la economía del bienestar establece condiciones bajo las cuales cualquier equilibro de precios con transferencias, y en particular cualquier equilibrio walrasiano, constituye un óptimo de Pareto. Para una economía de mercado competitiva proporciona una confirmación formal y muy general de la afirmación de Smith de que una 'mano invisible' dominaba la propiedad del mercado" (Mas-Collel y otros, 1995: 549; véase también: 327 y 524). 
La fuente del debate en torno a Smith y la teoría del equilibrio económico general se concentra principal, pero no exclusivamente, en el Capítulo 7, "Del precio natural y del precio de mercado de los bienes", en el primer libro de $R N$. Éste sería el supuesto fundamento de la teoría del equilibrio general, o el germen de la misma. Según Smith el precio natural difiere del precio de mercado (o real) que se determina según la demanda efectiva. Él define este proceso de la siguiente manera:

El precio natural es, en consecuencia, por decirlo así, el precio central, en torno al cual gravitan continuamente los precios de todos los bienes. Diversos accidentes pueden a veces mantenerlos suspendidos durante largo tiempo por encima de aquél, y en ocasiones los obligan a descender incluso a un nivel algo inferior. Pero cualesquiera sean los obstáculos que les impidan asentarse en este centro de reposo y permanencia, ellos tienden constantemente hacia él. ( $R N$ I.vii.15, 75, sin destacar en el original.)

La idea de todos los precios, el uso de la palabra gravitar, y la idea de un centro de reposo aparecen como evidencia adicional de la influencia de Newton, pero también debemos recordar que "[e]n los tiempos de Smith invocar el nombre de Newton y tomar prestada su terminología era un recurso retórico de uso común” (Redman, 1993: 225). Tras un par de páginas en que se analizan algunos aspectos sobre la manera en que las fluctuaciones de precios afectan la renta, los sueldos y las utilidades, Smith prosigue:

Pero aunque el precio de mercado de cada bien en particular se encuentra de este modo permanentemente gravitando, por así decirlo, en torno al precio natural, sin embargo en ocasiones ciertos accidentes, a veces causas naturales, o bien determinados regulaciones particulares pueden, en el caso de muchos bienes, mantener elevado el precio de mercado de manera continuada durante largo tiempo, en un nivel bastante superior al del precio natural. ( $R N$ I.vii.20, 77, sin destacar en el original.)

Nótese que tras gravitando Smith se cuida de añadir "por así decirlo”, tal vez para subrayar su carácter metafórico, o quizás consciente de que el término "gravitación" implicaba en realidad un fenómeno distinto. En verdad el uso que Smith hace del término gravitación en función de los precios emula la tercera ley de Newton de acción y reacción: “a cada acción corresponde siempre una reacción igual y contraria”, pero entre ambos se observan importantes diferencias. Para Newton la acción y la reacción son 
siempre iguales, y los cuerpos están gravitando no sólo en torno a algún cuerpo central, sino que todos ellos se encuentran gravitando mutuamente, unos en torno a otros. En otras palabras, si la descripción que Smith hace del mecanismo de precios fuera efectivamente newtoniana, todos los precios deberían gravitar unos en torno a otros, lo cual implica que el precio natural también debería gravitar en torno a los "precios de todos los bienes". El fenómeno anterior se asemejaría bastante a una suerte de desequilibrio. El difunto Bernard Cohen sostuvo que, debido a esta diferencia, la aplicación que Smith hizo del newtonianismo al mecanismo de precios "fue perfectamente correcta hasta cierto punto; fue simplemente incompleta" (Cohen, 1994: 65, destacado en el original). Se trata de una argumentación seria que contradice cualquier interpretación de la figura Smith como la de un precursor del equilibrio general que se basó en el pensamiento de Newton.

Otro punto de discrepancia es que la teoría del equilibrio general, desde los tempranos aportes de Walras, ha adquirido un carácter progresivamente matemático, emulando básicamente los resultados de lo que Cohen (1980) denomina el "estilo newtoniano" de Principia. Con todo, cabe recordar que Smith es muy cauteloso, y más bien escéptico, respecto al uso de las matemáticas en la filosofía moral (lo cual incluía, por cierto, la economía política). En una carta en que se refiere a la recopilación que Webster realizó de cifras demográficas escocesas para un sistema de pensiones, Smith declara: "Usted sabe que tengo escasa confianza en la Aritmética Política, y esta historia no contribuye a mejorar mi opinión sobre aquella" (Correspondence, 288). Luego, en $R N$ Smith señala: "No tengo gran confianza en la aritmética política” ( $R N$ IV.v.b.30, 534). Si bien dentro de esta tradición iniciada por William Petty la aplicación de la aritmética política durante el siglo XVIII suponía un alto grado de conjetura, por lo menos puede admitirse que el método de Smith en la teoría económica (y con mayor razón en la ética), con excepción de algunas operaciones aritméticas sencillas como porcentajes, no es matemático.

Además, en lo relativo a la visión teleológica de Smith sobre el mercado, él está considerando un proceso, no un estado final. Mark Blaug ha expresado este punto de vista de manera franca y directa:

El esfuerzo realizado en los libros de texto modernos por apoyarse en el pensamiento de Adam Smith para respaldar lo que hoy se conoce como los "teoremas fundamentales de economía del bienestar" es un travesty histórico de grandes proporciones. En primer término, la concepción de Smith sobre la 
competencia era [...] una concepción en función de un proceso y no de un estado final. (Blaug, [1962] 1997: 60.) (11 $^{21}$

Smith no compartía la idea de un reduccionismo mecánico que, aplicado a la teoría económica, exigiría el uso de las matemáticas avanzadas para explicar la armonía de las fuerzas del mercado al interior de un modelo idealizado de equilibrio general. Este reduccionismo presupone la existencia de un sistema cerrado, hipótesis que constituye la esencia de la teoría económica neoclásica, especialmente en relación con la teoría del equilibrio general. La economía política de Smith es la de un sistema abierto.

La convicción de que los fenómenos sociales pueden ser tratados de manera mecánica, y los individuos de manera atomística, ha sido erróneamente atribuida a algo que podría denominarse "newtonianismo smithiano". Este último corresponde a una interpretación doblemente espuria de Newton y Smith que se ha propagado entre ciertos economistas neoclásicos y que habría servido de fundamento para la formulación de teorías modernas sobre equilibrio económico general. Si los economistas se han limitado a relegar el newtonianismo a fuerzas en equilibrio, pasando por alto el verdadero significado de las leyes de Newton y la compleja metodología que éste aplicó, ese orden mecánico no necesariamente deriva de la concepción de Smith sobre el mecanismo del mercado. La descripción realista que Smith hace de los fenómenos económicos no allanó el terreno para la presuposición ontológicamente atomista-mecanicista de la economía neoclásica, de la cual el equilibrio económico general ha sido un epítome.

Por último, la fe incondicional en un orden racional, caracterizado por la armonía, la estabilidad, la nivelación o el equilibrio, fue un fenómeno característicamente francés, generalizado en Lavoisier, Laplace, Condillac, Lagrange y Condorcet. Esta tradición condujo a Walras. Sin embargo, los pensadores de la Ilustración Escocesa, y Smith en particular, no consideraban que los fenómenos sociales pudieran ser reducidos simplemente a un tipo de equilibrio mecánico. La verdad es que Smith utiliza sólo una vez la palabra "equilibrio" en $R N$, cuando critica la doctrina de la balanza comercial ( $R N$ IV.iii.c.2, 489). En este contexto, la manera en que Smith interpretó el pensamiento de Newton se relaciona directamente con la manera en que los escoceses asimilaron el newtonianismo, como sostengo en la próxima sección. El papel que le cupo a la Ilustración Escocesa en la difusión de las ideas de Newton es una importante característica que arroja más luz sobre el contexto del enfoque que Smith aplica al analizar la metodología de Newton.

${ }^{21}$ Winch también refuta convincentemente a aquellos que persisten en ver a Smith como un precursor de la teoría del equilibrio general, pero tampoco vacila en sugerir que "lo que Smith elogió como 'método newtoniano' se adapta a sus propias obras, lo mismo que a las de los teóricos del equilibrio general” (1997: 399). 


\section{Newton y la Ilustración Escocesa}

Justo en el último párrafo de Opticks, en la cuestión 31, Newton declaró "[y] si la Filosofía natural y todas sus Partes, siguiendo este método, se perfeccionaran completamente, también se ensancharían los Límites de la Filosofía Moral” (Newton, [1704] 1979: 405). Esta frase fue tomada en serio por los sabios del siglo XVIII. George Turnbull reprodujo esta cita en la portada de la primera edición de The Principles of Moral Philosophy (1740). Francis Hutcheson, padre de la Ilustración Escocesa, procuró establecer una moral matemática, probablemente inspirado por Newton. David Hume, por su parte, deseaba estructurar su "ciencia del hombre" emulando explícitamente el método experimental de Newton. Smith no fue una excepción en este escenario. Por tanto, como ya se señaló, no resulta sorprendente que se refiera a “[l]a gran obra de Sir Isaac Newton” (TSM III.2.20, 124). Thomas Reid fue otro heredero de esta tradición newtoniana, como lo revelan sus explícitas referencias a las "cuatro reglas [de Newton] para el estudio de la filosofía natural”. La influencia de Newton en la filosofía moral, las matemáticas, la economía política, la fisiología, la medicina, entre otras disciplinas, es enorme y muy compleja. Pero una de las preguntas más enigmáticas es cómo entendieron estos intelectuales el método de Newton.

En consecuencia, no debería sorprendernos que Smith también pudiera haberse hecho eco del deseo que Newton expresa al final de Opticks:

a la manera de Sir Isaac Newton, podemos sentar ciertos principios conocidos o demostrados en un comienzo, a partir de los cuales explicamos los diversos Fenómenos, asociándolos todos en una misma Cadena. Este último fenómeno, que podríamos llamar el método newtoniano es sin duda el más filosófico, y en toda ciencia, ya sea que se trate de la moral o de la filosofía natural, etc., resulta muchísimo más ingenioso y por lo mismo más atractivo que el otro [el de Aristóteles]. (Lectures on Rethoric and Belles Lettres [LRBL], lección 24, ii.133, 145-146, sin destacar en el original. $)^{22}$

${ }^{22}$ Cabe señalar como advertencia que este pasaje aparece publicado en una época en que Smith dictaba una cátedra sobre métodos de presentación. Hay otra referencia incidental a Newton en $L R B L$, Languages, 1 , 204, y en $L J$ (B), 399, además de una referencia a Representation to the Lords of the Treasury de Isaac Newton en una nota a pie de página de $R N$ I.xi.h, 229. Resulta muy importante la referencia a la filosofía newtoniana en la carta que Smith envió a los autores de The Edinburgh Review (EPS, 244). 
Si bien definir en qué consiste exactamente el newtonianismo es una tarea muy difícil y plagada de matices, la Ilustración Escocesa desempeñó un papel esencial en la difusión de esa corriente ${ }^{23}$. En efecto, Paul Wood ha sostenido recientemente que "sus escritos [los de Newton] fueron interpretados de maneras tan radicalmente distintas que cuesta identificar una tradición newtoniana unificada en las ciencias morales” (Wood, 2003: 802). Los philosophes del siglo XVIII adoptaron cuidadosamente los exitosos descubrimientos de Newton como un paradigma, pero muchos de ellos adaptaron descuidadamente su metodología. A mi juicio en Francia hubo una tendencia a interpretar a Newton dentro de un contexto en el que las instituciones científicas respaldaban aún el legado cartesiano. Los escoceses no sólo difundieron con resolución la herencia de Newton, sino que además poseían una concepción diferente de lo que era el newtonianismo, la cual determinó la manera en que los británicos recibieron el pensamiento de Newton. En mi opinión, este contexto podría ayudarnos a explicar por qué Smith comprendió tan bien a Newton.

Existen evidencias de que las universidades escocesas no sólo eran eminentemente newtonianas, sino que además cumplieron un papel decisivo en el establecimiento el newtonianismo en Gran Bretaña. A partir de la década de 1690 ellas “encabezaron la institucionalización del sistema newtoniano” (Wood, 2003: 810). Christine Shepherd (1982) ha realizado investigaciones en archivos acerca de la rápida aceptación que tuvo Newton en las universidades escocesas desde la década de 1660 hasta comienzos del siglo XVIII, y ha llegado a la conclusión de que Escocia fue escena de "un considerable grado de progreso en la filosofía natural a fines del siglo XVII y durante los primeros años del siglo XVIII” (ibídem: 83) ${ }^{24}$. Este fenómeno obedeció sin duda a la enorme influencia de los Gregories en Saint Andrews y en Edinburgo ${ }^{25}$, pero de ningún modo es atribuible exclusivamente a ellos. Por ejemplo, John Keill (1671-1721), matemático y pensador escocés, al pare-

${ }^{23}$ Shepherd (1982) y Wood (2003) han demostrado de manera notable cómo los intelectuales escoceses contribuyeron a difundir el newtonianismo en Gran Bretaña.

${ }^{24}$ Brockliss (2003) señala que "hacia la década de 1690 su teoría de la gravitación universal [la de Newton], al igual que sus trabajos sobre la luz y el color, estaban siendo debatidos por profesores de filosofía en las universidades escocesas” (ibídem: 47).

${ }^{25}$ James Gregory (1638-1675), inventor del telecopio reflector, fue miembro de la Royal Society, mantuvo correspondencia con Newton, llegó a ser profesor de matemáticas en Saint Andrews en 1668, y luego profesor de la Universidad de Edinburgo en 1674, ocupando la nueva cátedra de matemáticas. David Gregory (1659-1708) sucedió a su tío James Gregory como profesor de matemáticas en la Universidad de Edinburgo en 1683. En 1692 fue admitido en el Balliol College de Oxford, y posteriormente, con el respaldo de Newton, le fue asignada la cátedra saviliana de astronomía en Oxford. Fue un importante discípulo de Newton y miembro de su círculo íntimo. 
cer ya en 1699 comenzó a dictar cátedras sobre la filosofía natural de Newton en Oxford, y llegó a ocupar la cátedra saviliana en 1712, iniciando un curso experimental sobre física newtoniana ${ }^{26}$.

En Gran Bretaña tal vez las descripciones más influyentes y populares del nuevo sistema de Newton durante la primera mitad del siglo XVIII fueron A View of Sir Isaac Newton's Philosophy, de Henry Pemberton (1694-1771), publicada en 1728, un año después de la muerte de Newton, y The Elements of Sir Isaac Newton's Philosophy (1738), de Voltaire (16941778). Pero An Account of Sir Isaac Newton's Philosophical Discoveries, el notable tratado de Colin Maclaurin (1698-1746) publicado en 1748, es tal vez la mejor obra sobre el tema escrita en la primera mitad del siglo XVIII ${ }^{27}$.

Colin Maclaurin fue un matemático escocés extraordinariamente talentoso, quien en una época temprana de su vida, cuando sólo contaba 15 años, expuso una compleja tesis en la que explicaba la ley de gravedad de Newton. Asimiló rápidamente el cálculo newtoniano y "hay motivos para afirmar que fue el exponente más capaz y enérgico del newtonianismo en Escocia, cuando no en Gran Bretaña, durante la primera mitad del siglo XVIII. Él contribuyó no sólo a consolidar la influencia newtoniana en los círculos académicos escoceses, sino además a crear una ciencia pública dentro de la Ilustración Escocesa” (Wood, 2003: 102). Maclaurin captó la importancia y la esencia del legado de Newton, y la influencia que ejerció en Escocia y en Inglaterra a través de An Account of Sir Isaac Newton's Philosophical Discoveries fue considerable. Adam Smith fue precisamente otro sabio que aprovechó la refinada interpretación de Newton por parte de Maclaurin; aun cuando al parecer este libro no estaba en su biblioteca, hay fundadas razones para creer que sí lo leyó 28 .

${ }^{26}$ De acuerdo con su sucesor, Desaguliers, John Keill fue el primero en enseñar física newtoniana "mediante experimentos al modo matemático" (citado en Guerlac, 1981: 118).

${ }^{27}$ Inicialmente, la contribución de Maclaurin fue concebida como un complemento de una biografía de Newton proyectada por Conduitt, quien estaba casado con la sobrina de Newton, Catherine Burton. Tras el fallecimiento de John Conduitt en 1737, Colin Maclaurin continuó trabajando en su proyecto que finalmente fue publicado dos años después de su muerte (véase Strong, 1957: 54). Otras obras populares e influyentes fueron Sir Isaac Newton's Philosophy Explain'd for the Use of the Ladies (1737), de Francesco Algarotti (1712-1764), y The Elogium of Sir Isaac Newton (1728), el célebre libro de Bernard de Fontenelle (1657-1757). Notable resulta The Newtonian System of Philosophy, adapted to the Capacities of Young Gentlemen and Ladies (1761), que contiene las famosas enseñanzas de Tom Telescope (véase Secord, 1985).

${ }^{28}$ En su biblioteca sólo se encuentra A Treatise of Fluxions de Maclaurin (véase Bonar, 1966: 107). Pero cuando Smith se refiere a las observaciones de Cassini menciona a Maclaurin, “quien fue más capaz de juzgar” (“Astronomy” IV.58, 90). La anterior es una razón de peso para creer que Smith estaba familiarizado con An Account of Sir Isaac Newton's Discoveries, la famosa y popular obra de Maclaurin. 
La recepción de las ideas de Newton en Francia, así como el contexto en que ello ocurrió, fueron completamente distintos en comparación con Gran Bretaña. En un principio fue gracias a sus trabajos en el área de la óptica y a su telescopio reflector que Newton adquirió renombre en los círculos científicos franceses. La obra Principia no fue ignorada en Francia, sino simplemente refutada dentro de un marco cartesiano. Asimismo, Huygens y Leibniz fueron calificados críticos de la ley de gravedad de Newton, y como herederos de la filosofía mecánica cartesiana, hicieron todo lo posible por explicar la materia y su interacción como una causa de la gravedad. Si en Francia resultaba difícil aceptar la noción de un vacío, la idea de cuerpos que se atraen entre sí sin ninguna causa material fue en general considerada absurda. En realidad la noción más arraigada en Francia era la insistencia en los mecanismos y el contacto entre los cuerpos. Esta última idea estaba en conflicto con lo que proponía Newton en cuanto a la existencia de la gravitación universal como una fuerza que opera a nivel universal e independientemente de cualquier contacto mecánico directo. Descartes había definido la materia como un plenum que se extiende infinitamente, pero Newton formuló su concepto de una gravitación universal que opera en los cuerpos in vacuo.

La célebre obra de Voltaire, Letters Concerning the English Nation $(1733)^{29}$, no sólo popularizó la figura de Newton, sino que además reveló el contexto de una gran división entre el cartesianismo francés y el newtonianismo británico. El nuevo sistema de filosofía natural debía abrirse paso a través del sólidamente establecido régimen cartesiano, que estaba profundamente institucionalizado en la comunidad científica francesa ${ }^{30}$. Sólo por citar un ejemplo, si bien en Escocia la Universidad de Glasgow tardó más en aceptar inicialmente el newtonianismo, ya en 1711 se transformó en parte de la red newtoniana con la elección de Robert Simson (1687-1768) para ocupar una cátedra de matemáticas (Wood, 2003: 100). En la Universidad de París las primeras cátedras newtonianas se impartieron en la década de 1740, pues dicha institución había permanecido bajo el imperio del cartesianismo (véa-

${ }^{29}$ Especialmente la Carta XIV, “On Des Cartes and Sir Isaac Newton”, y en menor medida la Carta XV, “On Attraction”, y la Carta XVI, “On Sir Isaac Newton's Opticks”. Tengo una deuda de gratitud con Eric Schliesser por señalar que Voltaire también publicó un tratado independiente en 1738 como un libro (bastante largo), titulado Elémens de la Philosophie de Neuton.

${ }^{30}$ Como ha sostenido Guerlac (1981), fueron Malebranche y sus discípulos, especialmente Maupertius y Clairaut, quienes difundieron el legado de Newton en Francia, aunque también se ha señalado que ellos básicamente procuraron reconciliar a Newton con Descartes (véase Gascoigne, 2003: 299). Sobre la poderosa influencia que ejercieron Malenbranche y sus seguidores para que Newton fuera aceptado en Francia, véase Hankins (1967). 
se Jacob 1988: 201). De hecho "[d]ada la tenacidad con que los miembros de la Académie des Sciences francesa intentaron encontrar durante las primeras tres décadas del siglo XVIII una defensa matemática del vórtice cartesiano $[\ldots]$ no resulta sorprendente que la física fenomenológica de Newton haya tardado en echar raíces en los colleges y universidades de la Europa continental” (Brockliss, 2003: 61, véase también: 85). Gran Bretaña, siguiendo una tradición iniciada por Francis Bacon, dio mayor énfasis a la "filosofía experimental" de Newton. Lo anterior dio origen a dos tradiciones opuestas en el ámbito de la física: "una matemática y una experimental, que desde entonces han afectado los enfoques que ambos países aplican a la ciencia natural" (ibídem: 86). Fue sólo a fines del siglo XVIII cuando Laplace, quien se autodenominó "el Newton francés", logró finalmente imponer su propia "agenda newtoniana a la comunidad científica francesa" (Brockliss, 2003: 85).

Pero el desarrollo de ambas tradiciones estuvo estrechamente vinculado a la historia de las matemáticas. Aun cuando Guicciardini (1989) ofrece una visión más matizada, Florian Cajori, en su influyente obra A History of Mathematics (1901), declaró:

Los estudios matemáticos en el pueblo inglés y el alemán se han sumido en la más profunda decadencia [1730-1820]. Entre otros problemas, se escogió erróneamente la orientación de la investigación. Mientras el primero adhirió con excesiva parcialidad a antiguos métodos geométricos, el segundo creó la escuela combinatoria, la cual no produjo nada de valor. Los trabajos de Euler, Lagrange y Laplace se fundan en el análisis superior, y esa es un área que ellos desarrollaron en un grado extraordinario. (Ibídem: 246.)

Este juicio categórico sigue siendo objeto de debates, y muchas publicaciones han demostrado que es exagerado. Con todo, para expresarlo en términos sencillos, había una diferencia. Si en Gran Bretaña se aplicó el enfoque geométrico a las matemáticas, iniciado por Newton, los franceses siguieron otro camino. Este enfoque analítico, pese a arrojar mejores resultados, es muy distinto de lo que los escoceses entendían por ciencia. Era teórico pero no siempre práctico; era elegante pero no siempre real. En cuanto al papel de las matemáticas, la tradición escocesa interpretó la idea subyacente en Newton de que las matemáticas son un instrumento para describir la naturaleza y no un modelo de la realidad ${ }^{31}$. Asimismo, por lo

${ }^{31}$ Guicciardini (1989) presenta un análisis de las matemáticas en Gran Bretaña durante el siglo XVIII. 
general concebían las matemáticas, y en particular el cálculo diferencial, dentro de la tradición geométrica iniciada involuntariamente por Newton. La superioridad de las matemáticas analíticas y del pensamiento abstracto fue más generalizada y gozó de mayor aceptación dentro de la Ilustración Francesa. La mente matemática escocesa fue profundamente influida por el enfoque geométrico de Colin Maclaurin y Robert Simson (véase Olson, 1971).

La idea de una pugna entre la filosofía mecánica cartesiana y el newtonianismo no es original ${ }^{32}$, ni puede defenderse como un fenómeno generalizado. Pero a mi modo de ver existen fundamentos para suponer que Gran Bretaña y Francia apoyaron a sus respectivos héroes intelectuales. Además, no sólo fue Escocia una temprana defensora del newtonianismo, sino que también se advierte un aspecto más importante, y es que la Ilustración Escocesa proporcionó un marco único para asimilar y aplicar rápidamente enfoques originales a las ideas de Newton. La filosofía natural generó un debate acerca de la metafísica en general (véase Stein, 2002), y sobre la teología y la filosofía moral. La divergencia en cuanto a la naturaleza de la gravedad y la naturaleza de la materia conllevaba diversos aspectos metafísicos y teológicos. Esta discusión resultó ser especialmente fructífera en Escocia, y fue gracias a los escoceses que Gran Bretaña se volvió rápidamente newtoniana.

Las diferencias metodológicas entre las tradiciones de pensamiento francés y británica son consecuencia del legado de Newton, pero de ningún modo forman parte del mismo. El patriotismo, las rivalidades personales, las distintas agendas científicas, las idiosincrasias políticas y culturales, entre otros factores, contribuyeron a esta división. Si Francia en general fomentó un método axiomático-deductivo, y Gran Bretaña una metodología inductiva basada en los experimentos y la observación, Newton propugnó un proceso de aproximación continua a la realidad enmarcado por un método analíticosintético. Lo anterior confirma la tesis de que Adam Smith fue un refinado intérprete de la metodología de Newton, pero el contexto escocés podría haber sido más que una simple influencia indirecta en Smith.

${ }^{32}$ Sobre la recepción que las ideas de Newton tuvieron en Francia, en su obra L'Introduction des Théories de Newton en France au XIII Siècle I: Avant 1738 (el segundo tomo nunca apareció), Pierre Brunet señala que los cartesianos se opusieron al newtonianismo en Francia, pero Guerlac (1981) sostiene que no hubo tal división académica. Véase también Hall (1975). Por cierto que Opticks de Newton gozó de mayor popularidad, especialmente gracias a Malebranche y sus discípulos, y a Eloge, la célebre obra de Fontenelle, leída por primera vez ante la Royal Academy of Sciences en París en 1727. Un aspecto curioso, pero representativo, del cisma entre británicos y franceses es que en Francia (y en Europa continental) se adoptó la notación de Leibniz para el cálculo, mientras que en Gran Bretaña la notación de Newton prevaleció durante el siglo XVIII. Se trata de la famosa polémica del "punto contra las d". 


\section{Conclusión}

En este ensayo he procurado revelar en qué consistió realmente el newtonianismo, argumentando que Smith fue un refinado intérprete de la verdadera metodología de Newton. Al cuestionar la visión generalmente aceptada según la cual Smith, basándose en la extendida influencia de Newton, sería el padre de la teoría del equilibrio económico general, sostuve que, por algunas importantes razones metodológicas, ni Adam Smith ni tampoco Newton pueden ser considerados precursores de esta teoría. Si la teoría del equilibrio económico general se funda en una metodología axiomático-deductiva, y si su evolución ha estado estrechamente asociada a un desarrollo matemático, la metodología de Newton era más matizada.

En mi opinión, una interpretación cuidadosa del legado de un autor debería resaltar no sólo lo que el autor dijo, sino por qué y cómo lo dijo, vale decir que el texto, el contexto y el lenguaje cumplen un papel significativo e interdependiente. El verdadero significado de las ideas requiere más que un simple análisis textual. Creo que el éxito de la historia intelectual reside en la a menudo esquiva combinación de cada una de estas tres componentes. Al hacerse hincapié sólo en el texto se correría el riesgo de leer a un autor como si el texto hubiera sido escrito por un contemporáneo (una práctica habitual cuando se lee a Adam Smith como un economista moderno). Al concentrarnos exclusivamente en el contexto podríamos dejar de captar la verdadera esencia de lo que dice el texto y la intención del autor al usar determinadas palabras. El que las palabras, aparentemente sencillas, pero el mismo tiempo profundamente complejas, tienen verdadera importancia, es una verdad que trasciende a Wittgenstein. Sin embargo, al ponerse excesivo acento sólo en los enfoques hermenéuticos à la Foucault, se correría el riesgo de desencadenar un proceso en el que el autor y su contexto podrían simplemente desaparecer.

En la teoría económica generalmente hemos dado por sentada la existencia de una suerte de equilibrio económico en el pensamiento de Smith, un germen que se desarrolló en una dirección por todos conocida. Las referencias comunes a la mano invisible reflejan esta visión popular y generalizada. Sin embargo, el equilibrio de Newton aplicado a la teoría económica se transformaría más bien en un tipo de desequilibrio. Por otra parte, a nivel de la historia de las ideas sostuve que se produjo un cambio de rumbo científico e histórico. Si la Ilustración Escocesa tenía una manera "geométrica” de entender la realidad, poderosamente influida por Newton, fue una transición en la Europa continental, especialmente en Francia, lo que prepa- 
ró el camino hacia la formulación de la teoría del equilibrio económico general. La percepción anterior tiene connotaciones realistas que contrastan con un énfasis en la abstracción. Muchas reconstrucciones y especulaciones racionales pueden derivar de esta intuición, pero una consecuencia involuntaria de esta investigación es que Adam Smith, como miembro de la Ilustración Escocesa, comprendió el newtonianismo mucho más claramente de lo que se ha admitido en general.

\section{REFERENCIAS BIBLIOGRÁFICAS}

\section{a) Abreviaciones y referencias de las obras citadas de Adam Smith}

$\begin{array}{ll}\text { Corr. } & \text { Correspondence of Adam Smith. } \\ \text { EPS } & \text { Essays on Philosophical Subjects. } \\ \text { “Astronomy" } & \text { "History of Astronomy" (incluido en EPS). } \\ \text { LJ } & \text { Lectures on Jurisprudence. } \\ \text { LRBL } & \text { Lectures on Rethoric and Belles Lettres. } \\ R N & \text { La Riqueza de las Naciones } \\ & \text { [WN, The Wealth of Nations]. } \\ T S M & \text { La Teoría de los Sentimientos Morales } \\ & \text { [TMS, The Theory of Moral Sentiments]. }\end{array}$

Las referencias siguen las divisiones, párrafo(s) y finalmente página(s) de las ediciones en inglés de Liberty Fund, que son reproducciones fotográficas de las publicadas por Oxford University Press, basadas a su vez en la edición emprendida por la Universidad de Glasgow:

(Corr.) Correspondence of Adam Smith. E. C. Mossner e I. S. Ross (eds.). Indianápolis: Liberty Fund, 1987 [Oxford University Press, 1977, 1987].

(EPS) Essays on Philosophical Subjects. W. P. D., Wightman y J. C. Bryce (eds.). Indianápolis: Liberty Fund, 1982 [Oxford University Press, 1980].

(LJ) Lectures on Jurisprudence. R. L. Meek, D. D. Raphael y P. G. Stein (eds.). Indianápolis: Liberty Fund, 1982 [Oxford University Press, 1978].

$(L R B L)$ Lectures on Rethoric and Belles Lettres. J. C. Bryce (ed.). Indianápolis: Liberty Fund, 1985 [Oxford University Press, 1983].

(RN) An Inquiry into the Nature and Causes of the Wealth of Nations [WN 1776]. R. H. Campbell y A. S. Skinner (eds.). Indianápolis: Liberty Fund, 1981 [Oxford University Press, 1976, 1979].

(TSM) The Theory of Moral Sentiments [TMS 1759]. D. D. Raphael y A. A. Macfie (eds.). Indianápolis: Liberty Fund, 1984 [Oxford University Press, 1976, 1979]. 


\section{b) Otros autores citados}

Arrow, K. J. and Hahn, F.: General Competitive Analysis. San Francisco: Holden-Day Inc., 1971.

Blaug, M.: The Methodology of Economics or How Economists Explain. Cambridge: Cambridge University Press, [1980] 1992.

- Economic Theory in Retrospect. Cambridge: Cambridge University Press, [1962] 1997.

Brewster, D.: The Life of Sir Isaac Newton. London: John Murray, 1831.

- Memoirs of the Life, Writings, and Discoveries of Sir Isaac Newton. Edinburgh: Thomas Constable and Co, 1855.

Brockliss, L.: "Science, the Universities, and Other Public Spaces: Teaching Science in Europe and the Americas”. En R. Porter (ed.), The Cambridge History of Science, Eighteenth Century Science, Vol. 4. Cambridge: Cambridge University Press, 2003.

Brunet, P.: L'Introduction des Theories de Newton en France au XIII Siècle, I: Avant 1738. París: Libraire Scientifique Albert Blanchard, 1931.

Buchanan, J. M. and Yoon, J. Y.: “A Smithian Perspective on Increasing Returns”. En Journal of the History of Economic Thought, Vol. 22, No 1 (2000), pp. 43-48.

Cajori, Florian: A History of Mathematics. New York: The Macmillan Company, 1901.

Chandra, R.: “Adam Smith and Competitive Equilibrium”. En Evolutionary and Institutional Economics Review 1, 1 (2004), pp. 57-83.

Cleaver, K. C.: “Adam Smith on Astronomy”. En History of Science, Vol. 27, No 76 (1989), pp. 211-218.

Cohen, I. B.: The Newtonian Revolution. With Illustrations of the Transformation of Scientific Ideas. Cambridge: Cambridge University Press, 1980.

"Newton and the Social Sciences, with Special Reference to Economics, or, The Case of the Missing Paradigm". En P. Mirowski (ed.), Natural Images in Economic Thought "Markets Read in Tooth and Claw". Cambridge: Cambridge University Press, 1994.

Cohen, I. B. y G. E. Smith: The Cambridge Companion to Newton. Cambridge: Cambridge University Press, 2002.

Dow, S. C.: “The Scottish Political Economy Tradition”. En Scottish Journal of Political Economy, Vol. 34, № 4 (1987), pp. 335-348.

Fara, P.: “Marginalized Practices". En R. Porter (ed.), The Cambridge History of

Science, Eighteenth Century Science, Vol. 4, pp. 485-507. Cambridge:

Cambridge University Press, 2003.

Gleick, J.: Isaac Newton. New York: Pantheon Books, 2003.

Guerlac, H.: Newton on the Continent. Ithaca: Cornell University Press, 1981.

Guicciardini, N.: The Development of Newtonian Calculus in Britain, 1700-1800. Cambridge: Cambridge University Press, 1989.

- Reading the Principia. The Debate on Newton's Mathematical Methods for Natural Philosophy from 1687 to 1736. Cambridge: Cambridge University Press, 1999.

"Analysis and Synthesis in Newton's Mathematical Work”. En I. B. Cohen y

G. E. Smith (ed.), The Cambridge Companion to Newton. Cambridge:

Cambridge University Press, 2002. 
Hall, A. R.: "Newton in France: A New View”. En History of Science, Vol. 13 (1975), pp. 233-256.

Isaac Newton. Adventurer in Thought. Cambridge: Cambridge University Press, 1992.

Hetherington, N. S.: “Isaac Newton's Influence of Adam Smith's Natural Laws in Economics”. En Journal of the History of Ideas, Vol. 44, No 3 (1983), pp. 497505.

Hollander, S.: Classical Economies. Oxford: Basil Blackwell, 1987.

The Economics of Adam Smith. London: Heinemann Educational Books, 1973.

Jacob, M. C.: The Cultural Meaning of the Scientific Revolution. New York: A. A. Knopf, 1988.

Keynes, J. M.: “Newton, The Man”. En D. Moggridge (ed.), Essays in Biography, Vol. $\mathrm{X}$. The Collected Writings of John Maynard Keynes. London: Macmillan for the Royal Economic Society, 1972.

Kuhn, T. S.: “Newton’s Optical Papers”. En I. B. Cohen (ed.), Isaac Newton’s Papers \& Letters on Natural Philosophy. Cambridge: Cambridge University Press, 1958.

Lawson, T.: Economics \& Reality. London: Routledge, 1997.

Longuet-Higgins, H. C.: “The History of Astronomy: A Twentieth-Century View”. En P. Jones y A. Skinner (ed.), Adam Smith Reviewed. Edinburgh: Edinburgh University Press, 1992.

Maclaurin, C.: An Account of Sir Isaac Newton's Philosophical Discoveries. London: Printed for A. Millar, [1748] 1750.

Manuel, F. E.: Portrait of Isaac Newton: Cambridge, Massachusetts: Belknap Press of Harvard University Press, 1968.

Mas-Collel, A., M. D. Whinston y J. R. Gereen: Microeconomic Theory, Oxford: Oxford University Press, 1995.

McGuire, J. E.: “Newton's 'Principles of Philosophy': An Intended Preface for the 1704 Opticks and a Related Draft Fragment”. En British Journal for the History of Science, Vol. 5 (1970), pp. 178-186.

Montes, L.: "Smith and Newton: Some Methodological Issues Concerning General Economic Equilibrium Theory”. En Cambridge Journal of Economics, Vol. 27, No 5 (2003), pp. 723-747.

“Adam Smith: Real Newtonian”. En Sheila y Alisdair Dow (ed.), A History of Scottish Political Economy, pp. 102-122. London: Routledge, 2006.

Negishi, T.: “Adam Smith and Disequilibrium Economic Theory”. En The Adam Smith Review, Vol. 1 (2004), pp. 30-39.

Newton, I.: Opticks: or, a Treatise of the Reflections, Refractions, Inflections and Colours of Light. London: William Innys, [1704] 1979.

- Mathematical Principles of Natural Philosophy. Editado por I. B. Cohen y A. Whitman. Berkeley: University of California Press [1687] 1999.

Newton-Smith, W. H.: "Realism”. En R. C. Olby, G. N. Cantor, J. R. R. Christie y M. J. S. Hodge (ed.), Companion to the History of Modern Science, pp. 181-195, London: Routledge, 1990.

Olson, R.: "Scottish Philosophy and Mathematics 1750-1830". En Journal of the History of Ideas, Vol. 32, No 1 (1971), pp. 29-44. 
Redman, D. A.: “Adam Smith and Isaac Newton”. En Scottish Journal of Political Economy, Vol. 40, № 2 (1993), pp. 210-230.

Robbins, L.: An Essay on the Nature and Significance of Economic Science. New York: Macmillan and Co, [1932] 1962.

Samuelson, P.: "Economic Theory and Mathematics. An Appraisal". En American Economic Review, Vol. 33, № 2 (1952), pp. 56-66.

Schliesser, E.: “Some Principles of Adam Smith's 'Newtonian' Methods in the Wealth of Nations". En Research in History of Economic Thought and Methodology, Vol. 23A (2005), pp. 35-77.

"Realism in the Face of Scientific Revolutions: Adam Smith on Newton's 'Proof' of Copernicanism”. Por aparecer en British Journal for the History of Philosophy.

Schumpeter, J. A.: History of Economic Analysis. Routledge: London, [1954] 1994.

Secord, J. A.: "Newton in the Nursery: Tom Telescope and the Philosophy of Tops and Balls, 1761-1838”. En History of Science, Vol. 23 No 60 (1985), pp. 127151.

Shepherd, C. M.: "Newtonianism in Scottish Universities in the Seventeenth Century". En R. H. Campbell y A. S. Skinner (ed.), The Origins \& Nature of the Scottish Enlightenment. Edinburgh: John Donald Publishers Ltd., 1982.

Skinner, A. S.: “Adam Smith: An Aspect of Modern Economics?”. En Scottish Journal of Political Economy, Vol. 26, No 2 (1979), pp. 109-25.

"Adam Smith, the Philosopher and the Porter”. En P. L. Porta, R. Scazzierir y A. Skinner (ed.), Knowledge, Social Institutions and the Division of Labour. Cheltenham: Edward Elgar, 2001.

Smith, G. E.: "The Methodology of the Principia”. En I. B. Cohen y G. E. Smith (ed.), The Cambridge Companion to Newton. Cambridge: Cambridge University Press, 2002.

Spargo, P. E.: “Sotheby's, Keynes, and Yahuda: The 1936 Sale of Newton's Manuscripts”. En P. M. Harman y P. M. Shapiro (ed.), Investigations of Difficult Things: Essays on Newton and the History of the Exact Sciences in Honour of D. T. Whiteside. Cambridge University Press, 1992.

Stein, H.: “Newton's Metaphysics”. En I. B. Cohen y G. E. Smith (ed.), The Cambridge Companion to Newton. Cambridge: Cambridge University Press, 2002.

Strong, E. W.: "Newton's Mathematical Way”. En Journal of the History of Ideas, Vol. 12, $\mathrm{N}^{\mathrm{o}} 1$ (1951), pp. 90-110.

“Newton and God”. En Journal of the History of Ideas, Vol. 13, № 2 (1952), pp. 147-167.

“Newtonian Explanations of Natural Philosophy”. En Journal of the History of Ideas, Vol. 18, No 1 (1957), pp. 49-83.

Stukeley, W.: Memoirs of Sir Isaac Newton's Life. London: Taylor and Francis, [1752] 1936.

Voltaire: Letters Concerning the English Nation. Oxford: Oxford University Press, [1733] 1994.

Weintraub, E. R.: How Economics Became a Mathematical Science. Durham: Duke University Press, 2002.

Westfall, R. S.: Never at Rest: A Biography of Isaac Newton. Cambridge: Cambridge University Press, 1980. 
Westfall, R. S.: The Life of Isaac Newton. Cambridge: Cambridge University Press, 1993.

White, M.: Isaac Newton. The Last Sorcerer. London: Fourth Estate, 1998.

Winch, D.: “Adam Smith's Problems and Ours”. En Scottish Journal of Political Economy, Vol. 44, № 4 (1997), pp. 384-402. 